\title{
Psicologia e Democracia: da Ditadura Civil-Militar às Lutas pela Democratização do Presente
}

\section{Psychology and Democracy: from the Civil-Military Dictatorship to the Struggles for the Democratization of the Present}

\author{
Psicología y Democracia: de la Dictadura Civil-Militar a \\ las Luchas por la Democratización del Presente
}

\author{
Domenico Uhng Hur \\ Universidade Federal de Goiás, GO, Brasil.
}

\author{
Fernando Lacerda Júnior \\ Universidade Federal de Goiás, GO, Brasil.
}

\section{Psicologia e política}

O Conselho Federal de Psicologia (CFP) é uma autarquia de Estado que orienta e fiscaliza a profissão do(a) psicólogo(a). Mas não atua apenas pela melhoria do exercício profissional. Desde o início da década de 1980, o CFP e o Sistema-Conselhos de Psicologia perceberam que suas práticas não devem ficar restritas à normatização do exercício profissional e das técnicas psicológicas. Também devem atingir as questões sociais e políticas do país, tendo em vista a luta pela democratização dos processos sociais e políticos. Nos anos 1980, o CFP lutou pelos direitos humanos e pela democracia, equidade e igualdade, participando das mobilizações das "Diretas Já" e da “Constituição cidadã” (Hur, 2012). Na década de 1990, fomentou o lema da "Psicologia e o compromisso social”. Desde os anos 2000, adotou como bandeira a atuação da Psicologia nas políticas públicas. Esses posicionamentos e práticas resultaram na constituição de uma Psicologia plural e múltipla, que se exerce em inúmeros campos de trabalho, que tem um lugar de destaque nas políticas sociais e que assume um compromisso pela mudança e transformação psicossocial. Por exemplo, se compararmos o Brasil com outros países da América Latina, teremos uma porcentagem muito maior de psicólogas(os) contratadas(os) pelas diversas políticas públicas e que exercem atividades que vão além da clínica tradicional.

Deste modo, constata-se que o CFP assume posicionamento e práticas que visam a produção de uma sociedade mais igualitária, justa e democrática e, por conseguinte, com menor sofrimento psicossocial. Portanto, pode-se afirmar que suas ações são eminentemente políticas.

Por política não aludimos apenas ao que aparece no Poder Executivo, no Congresso Nacional, às práticas de corrupção ou outros dissabores que são transmitidos pelos meios de comunicação. Política refere-se às práticas de gestão da vida no espaço da polis, da cidade. Refere-se às relações incessantes de poder e de forças que são exercidas a todo momento nos espaços sociais e que têm como finalidade a gestão da vida (Hur, 2013). Compreende-se que o CFP, em suas práticas, sempre está exercendo relações de forças para a gestão da vida, isto é sempre está atuando politicamente, seja no âmbito da normatização da profissão, ou das lutas sociais.

No que tange à relação entre Psicologia e política, não só o CFP assume posicionamentos políticos, como também a própria Instituição Psicologia, seus saberes, dispositivos técnicos de intervenção e seus atores sociais (psicólogas[os]). Pois suas práticas sempre estão posicionadas social-historicamente e exercem relações de forças que culminam na gestão da vida, tanto individual, como social. É inegável que a atuação do psicólogo no Sistema Único de Assistência Social (SUAS) exerce relações de forças que podem transformar a vida da comunidade. É inegável que a atividade do psicólogo no seu consultório privado, ou mesmo um psicodiagnóstico, altera as relações de forças de um indivíduo consigo próprio e com seu entorno, no qual ele 
pode reconfigurar e assumir não só um novo posicionamento existencial, mas também político, porque se atualizam ali novas relações de forças e desejantes. Assim, as práticas da Psicologia sempre exercem forças que atuam na gestão da vida e da subjetividade. Assumem um posicionamento político que pode incitar processos de autonomia e desejantes, ou mesmo processos cerceadores e de bloqueio da vida. Podem estar implicadas com a emancipação e transformação, mas também com o seu reverso, seja a captura pelas estigmatizações e disciplinarizações, a opressão da violência de Estado, a exclusão promovida pelo neoliberalismo etc. Então, mesmo que parte das(os) psicólogas(os) tenha dificuldades em vislumbrar o caráter político de suas práticas profissionais, suas relações de forças e efeitos, sempre há produção de regimes de poder em suas intervenções profissionais. Não há neutralidade nas práticas psicológicas e, tampouco, nas científicas: há uma microfísica das relações de poder em todos os espaços e práticas sociais. Aqui vale citar uma máxima bastante emitida pelo Prof. Pedrinho Guareschi em suas conferências: "Se ignoramos a política, nos tornamos vítima dela”.

\section{Psicologia e ditadura civil-militar}

No Brasil e na América Latina, a produção acadêmica da Psicologia investigou os efeitos da violência de Estado e do regime de opressão das ditaduras que se deflagraram nas décadas de 1960 e 1970. Estes estudos não tiveram apenas finalidades psicoterápicas, de elaborar o trauma sofrido diretamente pelas vítimas do regime de exceção, mas também finalidades políticas, de produzir novas narrativas sobre o que ocorreu, diferente da versão da "história oficial". Os discursos sobre a memória são uma forma de elaboração dos horrores que se viveu, seja no Holocausto, ou nas ditaduras latino-americanas (Huyssen, 2002), e que visam a produção de uma "contra-história" (Foucault, 1999), na qual não se heroiciza os agressores e não se culpabiliza as vítimas, tal como ocorreu no discurso oficial no Brasil. A elaboração da memória e de histórias alternativas não é algo que fica estanque no passado, senão é uma produção incessante do presente (Vázquez, 2001), que conforma realidades e formas de ser que pavimentam um caminho para um futuro a se construir. A atividade mnemônica é uma cartografia, em que seu método, como diria Deleuze (1997), não é o de escavar para encontrar a tumba do faraó, mas de acompanhar os movimentos de deriva dos conti- nentes. Portanto, apreender a memória e o passado é a produção de um futuro e de devires, e não de algo que já passou e que está concluído. A construção da memória está em disputa, em conflito (Ansara, 2008; Dobles, 2009), principalmente no que se refere aos episódios de violência do Estado.

Dentre muitas obras da Psicologia sobre o tema que tiveram maior profusão na década de 1990, citamos apenas algumas publicadas no cone sul. Na Argentina, Janine Puget (Puget, 2000; Puget, \& Kaës, 1991) dedicou-se aos estudos e intervenções sobre os efeitos psíquicos e na memória da violência de Estado; no Chile, a equipe de Elizabeth Lira (Lira, Weinstein \& Kovalskys, 1987; Lira, \& Piper, 1997) produziu extensa obra a partir dos milhares de atendimento que realizaram; no Uruguai, o trabalho do casal Marcelo e Maren Viñar é referência para o estudo psicanalítico sobre a tortura, a violência e seus efeitos subjetivos (Viñar, 1992; Viñar, 1997). Já no Brasil, trabalhos seminais sobre o tema, e imprescindíveis para a área, são os livros de Naffah Neto (1985), sobre as situações de tortura, de Arantes (1994), sobre psicanálise e clandestinidade política e de Coimbra (1995), que faz uma análise pormenorizada sobre as práticas da Psicologia no período da ditadura civil-militar. A professora Cecília Coimbra se tornou a maior referência no país nas discussões sobre a Psicologia, ditadura e violência de Estado, tanto por sua produção acadêmica, como por sua intensa participação política. A fundadora do "Movimento Tortura Nunca Mais" não apenas investigou a violência do passado, como também as opressões que se atualizam hoje em dia, por exemplo, os abusos da violência policial-estatal. Seguramente podemos afirmar que todas(os) as(os) autoras(os) presentes nesse número temático foram inspiradas(os) por sua obra e palestras magistrais.

Em 2013, com a finalidade de ampliar a produção de pesquisas e textos que analisam a ditadura civil-militar no Brasil, o CFP, em parceria com a Comissão Nacional de Direitos Humanos (CNDH), organizou o "Prêmio de Psicologia e Direitos Humanos: ditadura civil-militar e repercussão sobre a Psicologia como Ciência e Profissão". Buscou-se estimular análises problematizando o regime autocrático e as possíveis implicações sobre a Psicologia. Foram recebidos 52 artigos de profissionais e estudantes de todo o Brasil. Com isso, ficou claro que há muitas psicólogas(os) interessadas(os) em discutir criticamente a história do regime autocrático e suas reminiscências no Brasil. Vale ressaltar que na data de 
premiação dos artigos vencedores, o CFP (2013) publicou o livro "A verdade é revolucionária: testemunhos e memórias de psicólogas e psicólogos sobre a ditadura civil-militar brasileira (1964-1985)", que contém as narrativas de dezenas de psicólogas(os) de todo o país que vivenciaram o período de exceção.

Infelizmente, as violências retratadas no período da ditadura civil-militar não ficaram restritas ao passado. As opressões, os ataques à democracia e aos direitos sociais ocorrem a todo momento, atingindo outro ápice na atualidade. A efetivação de mais um golpe político em 2016 (neste caso, parlamentar), a implementação acelerada de um programa de austeridade que penaliza trabalhadoras(es) e as classes mais pobres, os aprisionamentos políticos arbitrários, o desrespeito do Judiciário a uma de nossas mais caras resoluções (Resolução CFP n ${ }^{\circ}$ 01/1999 - Conselho Federal de Psicologia, 1999), e a censura a exposições artísticas etc. denotam o recrudescimento de posições conservadoras, coercitivas da vida e que prejudicam as maiorias sociais e as liberdades de se expressar e de ser.

A conjuntura atual sinaliza como a defesa da democracia é parte constituinte das lutas para a manutenção de direitos sociais e a criação de melhores condições sociais e políticas para a classe trabalhadora, que é a maior parte da população brasileira. No ano de 2017, durante as manifestações que ocorreram no Distrito Federal contra as reformas da previdência e trabalhista, o Exército foi utilizado para reprimir violentamente manifestações pacíficas de dezenas de milhares de pessoas. $\mathrm{O}$ fato do governo de Michel Temer mobilizar o Exército para reprimir pessoas que, legitimamente, lutavam contra a corrupção, em favor de eleições diretas e por direitos sociais, mostra a importância de entendermos as razões pelas quais a democracia ainda é tão frágil no Brasil. Isso significa olhar para nossa história e o presente criticamente e buscar perceber o que restou da ditadura civil-militar. Percebe-se que há uma estreita relação entre o que permanece da ditadura no processo de redemocratização e as recentes manifestações de parte da sociedade brasileira.

Deste modo, a discussão sobre a função política da Psicologia torna-se ainda mais relevante em face do atual quadro macropolítico enfrentado. Conside- ramos que a luta pelos direitos humanos e contra a exploração e opressões não é algo que ficou no passado, mas sim que se atualiza com os desafios colocados pelo presente. Atualizar a memória histórica das duras experiências da ditadura civil-militar se torna uma tarefa importante, na qual urge visibilizar e transmitir as produções de psicólogas(os) sobre as implicações ético-políticas da Psicologia relacionadas a este difícil momento histórico-social e suas lutas pela democratização do país. Dessa forma, a "Revista Psicologia: Ciência e Profissão” apresenta o número especial "Psicologia e democracia" para aglutinar e visibilizar essa produção. Consideramos que este volume é um marco histórico na Psicologia brasileira, pois é a primeira vez que um periódico acadêmico da Psicologia no país dedica integralmente um número temático para a discussão de sua relação com a ditadura civil-militar ${ }^{1}$.

Busca-se apresentar análises sobre como a ditadura civil-militar teve repercussões sobre a Psicologia como Ciência e Profissão, bem como a Psicologia contribuiu ou pode contribuir nas lutas emancipatórias pela democracia no Brasil e na América Latina. O tema deste número temático é ousado, pois apreende a Psicologia não apenas como conjunto de saberes ou dispositivos técnicos de intervenção, mas no seu compromisso enquanto Instituição social para a constituição de uma sociedade mais justa e democrática. Discute não apenas sua atuação profissional, mas sua implicação nas distintas relações de poder sociais, ou seja, a função política da Psicologia na história brasileira. De certa forma também se coloca a Psicologia no "banco dos réus", para analisar suas implicações com os processos políticos do país, se realmente esteve a serviço da democracia, ou se pode ter tido alguma relação com a opressão do período ditatorial. Infelizmente os estudos sobre a Instituição Psicologia no Brasil nos mostram que houve casos, não isolados, de contribuição para as práticas políticas opressivas no período da ditadura, e que podem estar sendo reatualizados até os dias de hoje.

Neste número temático, recebemos 34 propostas. A triagem seguiu os mesmos padrões usuais para a seleção e avaliação de artigos para dossiês temáticos em revistas científicas. Após análise da adequa-

\footnotetext{
${ }^{1}$ Vale citar que a Revista Psicologia Política organizou em 2015 um dossiê com temática próxima, sobre "O impacto psicossocial das Comissões da verdade e outros processos de justiça de transição em países de América Latina”. No entanto, diferentemente de nosso número temático, não contou com nenhum trabalho sobre o ocorrido no Brasil e seus cinco artigos focalizaram as experiências das Comissões da Verdade da Argentina, Equador, Paraguai, Peru e Uruguai (Páez, Espinosa, \& Beristain, 2015).
} 
ção dos manuscritos ao tema deste número especial, enviamos os trabalhos para avaliação por pareceristas ad hoc, doutores especialistas na área e com reconhecida trajetória científica no tema do artigo. O sistema utilizado foi o da "avaliação cega", na qual os pareceristas desconhecem a identidade do(a) autor(a) e vice-versa. Foram aprovados dezessete artigos de autores de todas as regiões do país e um do México. Dentre eles também constam cinco artigos vencedores do prêmio "Psicologia e Direitos Humanos: ditadura civil-militar e repercussão sobre a Psicologia como ciência e profissão ${ }^{2 "}$ de 2013.

Dentre a variedade de temáticas dos diversos artigos, agrupamos em quatro tópicos: a) Práticas e políticas da Psicologia na ditadura civil-militar; b) Psicanálise e testemunhos: clínica e política; c) Psicologia e os movimentos de raça, etnia e sociais e d) Desafios para a democratização do presente.

\section{Práticas e políticas da Psicologia na ditadura civil-militar}

Neste primeiro tópico agrupamos os artigos que se referem diretamente à reconstrução da memória e das narrativas no período da ditadura civil-militar. Os trabalhos versam sobre a relação entre as práticas e políticas da Psicologia no período de exceção.

Em "Psicología y destrucción del psiquismo: la utilización profesional del conocimiento psicológico para la tortura de presos políticos", David Pavón-Cuellar, da Universidad Michoacana de San Nicolás de Hidalgo (UMSNH - México), analisa a utilização da Psicologia para a tortura de presos políticos no mundo e especialmente na América Latina. Centra-se em casos ocorridos no México, Uruguai, Chile e Brasil, além de tecer considerações acerca do recente debate sobre os psicólogos torturadores da American Psychological Association, dos Estados Unidos.

Domenico Uhng Hur e Fernando Lacerda Júnior, da Universidade Federal de Goiás (UFG), em "Ditadura e insurgência na América Latina: Psicologia da Libertação e resistência armada" discutem como a luta insurgente de ex-guerrilheiros brasileiros e um das FARC (Forças Armadas Revolucionárias da Colômbia) contra o terrorismo de Estado no Brasil e na América Latina resultou na produção de novas ideias na Psico- logia, a Psicologia da Libertação, e como transformou as formas de participação política dos sujeitos que aderiram a práticas radicais de luta política.

Em "Luta armada na Psicologia: prática de classe contra o terrorismo de estado", Juberto Antonio Massud de Souza e Ana Maria Jacó-Vilela, da Universidade Estadual do Rio de Janeiro (UERJ), resgatam as trajetórias de estudantes e profissionais da Psicologia que participaram diretamente de organizações políticas que adotaram a luta armada como tática de combate à ditadura civil-militar. Ao demonstrarem que existiam estudantes, psicólogas e psicólogos que colocaram suas vidas em risco ou até mesmo morreram defendendo uma sociedade igualitária e democrática, os autores argumentam que a Psicologia não foi apenas um poço de práticas conservadoras e defendem a ideia de que as ações e os sacrifícios dos exemplos de luta citados no artigo podem ter contribuído para impulsionar debates e problematizações sobre as políticas da Psicologia no Brasil.

Filipe Boechat, da Universidade Federal de Goiás (UFG), em "A Psicologia brasileira nos ciclos democrático-nacional e democrático-popular", assume a tese de que a história da Psicologia como ciência e profissão no Brasil não pode ser compreendida de forma separada da história da formação social brasileira. Dessa forma, problematiza as diferentes propostas de Psicologia que emergiram em dois períodos específicos da sociedade brasileira. Mostra como a concepção "tradicional" de Psicologia que predominou nas primeiras décadas após a regulamentação da profissão esteve estreitamente relacionada com as necessidades dos aparelhos ideológicos do ciclo democrático-nacional da sociedade brasileira. O autor também elabora importante crítica sobre os limites do tipo de "Psicologia Crítica", que se tornou hegemônica após o processo de democratização da sociedade brasileira e destaca sua estreita articulação com os aparelhos ideológicos típicos do ciclo democrático-popular.

Em "O fazer psicológico no período da ditadura civil-militar", Ana Maria Batista Correia, da Universidade Federal do Piauí (UFPI), e Carla Náyad Castelo Branco Dantas, do Instituto Dom Barreto, discutem as práticas da Psicologia no período da ditadura civil-militar questionando se esta estava a serviço do

\footnotetext{
${ }^{2}$ Os artigos premiados já estavam pré-aprovados, mas também foram avaliados pelos mesmos critérios, passando por reformulações para se adequar ao formato da Revista. Na categoria profissional foram os de Hur \& Lacerda Jr. (2017), Jardim (2017) e Correia \& Dantas (2017). Os da categoria estudante foram os de Silva (2017) e Furlan (2017). A outra autora premiada na categoria estudante não submeteu seu artigo para este número temático.
} 
regime de opressão ou da sociedade. Para realizar tal reflexão, utilizam a perspectiva do psicólogo da libertação Ignácio Martín-Baró.

Fabiola Figueirêdo da Silva, da Universidade Federal de São Paulo (Unifesp), em "Psicologia no contexto da ditadura civil-militar e ressonâncias na contemporaneidade", busca refletir sobre a relação entre as práticas da Psicologia e suas entidades da classe profissional com a ditadura civil-militar. Ressalta a importância de uma Psicologia ética e comprometida socialmente com a realidade vivida.

Em "Psicologia e a política de direitos: percursos de uma relação", Vinicius Furlan, da Pontifícia Universidade Católica de São Paulo (PUC-SP), discute a relação da Psicologia com as políticas de direito nos períodos da ditadura civil-militar e da atualidade. Perscruta diferentes práticas que mostram como a Psicologia assume práticas mais progressistas, ao mesmo tempo em que há uma série de desafios diante da profissão.

Fazendo a transição com o presente, Luis Eduardo Franção Jardim, da Universidade de São Paulo (USP), em "Psicologia Social e pesquisa com memória: método e reparação de danos da ditadura civil-militar", discute as marcas que a ditadura civil-militar deixou na memória coletiva e individual. Apresenta o Clínicas do Testemunho e a Comissão da Verdade como práticas de justiça transicional e nos brinda com uma proposta metodológica de pesquisa com a memória a partir da Psicologia Social, que também pode contribuir neste processo.

\section{Psicanálise e testemunhos: clínica e política}

A psicanálise foi um dos principais dispositivos teórico-clínicos utilizados para elaborar os traumas e marcas da violência de Estado na América Latina. Os psicanalistas não se limitaram ao exercício técnico, mas também assumiram posicionamentos políticos em relação às ditaduras em nosso continente. Citamos como um exemplo inspirador as práticas do Grupo Plataforma, dissidência da Associação Psicanalítica Argentina. Devido ao seu aguerrido e crítico posicionamento, foi perseguido politicamente e muitos dos seus integrantes tiveram que se exilar em outros países (Rodrigues, Fernandes \& Duarte, 2001). Os artigos aqui apresentados referem-se às investigações psicanalíticas sobre os processos de escuta e construção das narrativas, em grande parte amparados no projeto de reparação e justiça transicional denominado de "Clínicas do testemunho".
Rafael Alves Lima, da Universidade de São Paulo (USP), em "Análise reparável e irreparável: o conceito psicanalítico de reparação na agenda da Transição brasileira", nos brinda com um importante arcabouço teórico ao discutir o conceito de reparação em distintas tradições teóricas da psicanálise. Fornece-nos importante material para a escuta de testemunhos de elaboração do passado, que insistem e persistem no presente.

Em "Reminiscências da violência estatal: a reparação psíquica através de uma Clínica Política”, Natália Centeno Rodrigues, Francisco Quintanilha Véras Neto e Rodrigo Fernandes Teixeira, da Universidade Federal do Rio Grande (FURG), discorrem sobre o processo de transição da ditadura civil-militar para a democracia. Focalizam as práticas reparatórias adotadas e a constituição do projeto responsável por fornecer a reparação psíquica, o supracitado Clínicas do Testemunho.

Já Alexei Conte Indursky e Bárbara de Souza Conte, da Associação Psicanalítica de Porto Alegre (Instituto Appoa), em "Reparação psíquica e testemunho", debatem a implementação do Projeto Clínicas do Testemunho, focalizando a experiência do dispositivo "Grupo de testemunho", enquanto uma via clínico-política nas políticas de reparação. Além dos processos psicoterápicos, focalizam também as políticas da reparação psíquica.

Em "O ensino testemunhal entre os restos da ditadura: uma metodologia ético-política”, Helena Pillar Kessler, Daniel Boianovsky Kveller, Marina da Rocha Rodrigues e Karine Shamash Szuchman, da Universidade Federal do Rio Grande do Sul (UFRGS), narram a experiência de uma disciplina de graduação que focalizou o que permanece da ditadura entre nós. Trauma, testemunho e crise foram conceitos cruciais utilizados para refletir sobre o ocorrido.

\section{Psicologia e os movimentos de raça, etnia e sociais}

Neste tópico apresentam-se os trabalhos relacionados a movimentos sociais, raciais e étnicos relacionados aos impactos da ditadura civil-militar. São abordadas as discussões sobre o negro, os indígenas e o maior movimento social latino-americano, o Movimento dos Trabalhadores Sem Terra (MST).

Lia Vainer Schucman, da Universidade de São Paulo (USP), e Hildeberto Martins, da Universidade Federal Fluminense (UFF), em "A Psicologia e o discurso racial sobre o negro: do 'objeto da ciência' ao sujeito político”, discutem como se modificaram as apreensões da Psicologia sobre os estudos raciais, 
desde o início do século XX até o período pós-redemocratização do país. Há um deslocamento de sentidos, no qual outrora a Psicologia abordava o negro como objeto, mas, seguindo a atualização de forças progressistas da abertura política, tomou-se as questões raciais a partir de um enfoque crítico e politizado, no qual este emerge como protagonista e importante ator social.

Em "Parecer psicossocial da violência contra os povos indígenas brasileiros: o caso Reformatório Krenak", Bruno Simões Gonçalves, da Universidade Federal Rural do Rio de Janeiro (UFRRJ), analisa algo pouco presente nos estudos tradicionais sobre a ditadura-civil militar: a violência estatal policial contra indígenas. Através de análise documental, viagem de campo e 23 entrevistas, o autor investigou o centro de detenção de indígenas que ficou conhecido como "Reformatório Krenak”, que funcionou entre 1969 e 1973.

Em "Práticas discursivas sobre a luta pela terra na transição democrática brasileira", Jáder Ferreira Leite, Magda Dimenstein e Candida Maria Bezerra Dantas, da Universidade Federal do Rio Grande do Norte (UFRN), narram o acontecimento do I Congresso Nacional do Movimento de Trabalhadores Sem Terra (MST). Ressaltam a relação do MST e da Comissão da Pastoral da Terra (CPT) com a reabertura política no país.

\section{Desafios para a democratização do presente}

A luta pela democracia é algo que se constrói e se faz no presente. Neste último tópico, contamos com artigos que refletem sobre o papel da Psicologia nas lutas contemporâneas, como pela laicidade, pela democratização da cidade e na luta contra a militarização do contemporâneo.

$\mathrm{O}$ artigo de Tatiana Lionço, da Universidade de Brasília (UnB), traz discussão extremamente relevante e atual pela qual a Psicologia passa e que foi recentemente visibilizada pela mídia do mundo inteiro. Em "Psicologia, democracia e laicidade em tempos de fundamentalismo religioso no Brasil", a autora defende a importância da laicidade para práticas democráticas e sociais na Psicologia. Neste contexto, analisa a ofensiva dos fundamentalismos religiosos e a denominada "Psicologia Cristã" contra normativas da profissão, tal como a Resolução CFP no 01/1999. Destaca, assim, as práticas e lutas do CFP em defesa da laicidade e de um exercício ético na Psicologia.

Em "Psicologia e democracia em um cenário de cidade como campo em disputa”, Elisa Martins,
Fhillipe Pereira, Gabriela Salem, Lucas Gabriel de Matos Santos e Roberta Brasilino Barbosa, da Universidade Federal do Rio de Janeiro (UFRJ), nos mostram a necessidade de práticas que visam democratizar o espaço urbano da cidade, bem como a subjetividade. Por meio de variados dispositivos coletivos de intervenção no Rio de Janeiro discutem o papel da Psicologia para os processos de democratização de uma cidade que constantemente nos vem sendo subtraída.

Ana Vládia Holanda Cruz, da Faculdade DeVry Fanor (Fortaleza/CE), Tatiana Minchoni, da Universidade Federal de Santa Catarina (UFSC), Adriana Eiko Matsumoto, da Universidade Federal Fluminense (UFF - Volta Redonda) e Soraya Souza de Andrade, da Universidade Federal do Pará (UFPA), em "A ditadura que se perpetua: direitos humanos e a militarização da questão social", discutem como a violência da ditadura se perpetua no presente nas práticas de militarização do contemporâneo. A partir da Criminologia Crítica refletem sobre a construção da figura do delinquente como inimigo interno, assim como da função dos processos de criminalização.

\section{Um convite}

A abertura de um espaço para discutir a democracia na Revista Psicologia: Ciência e Profissão significa que as(os) psicólogas(os) não podem ficar alheias(os) aos principais acontecimentos sociais e políticos que fraturam a sociedade brasileira. Pensamos que, além da discussão das implicações da Psicologia na transição da ditadura à democracia, a leitura desse número temático consiga incitar as(os) psicólogas(os) a fazer uma autoanálise de suas práticas profissionais, para refletirem sobre que regimes de poder estão sendo fomentados e reproduzidos. As questões que se colocam são: Suas práticas incitam processos de potencialização da vida e desejantes, ou opressores, normatizadores e despotencializadores? Favorecem as minorias privilegiadas ou as maiorias desfavorecidas socialmente? Beneficiam o chefe, o empresário, ou os trabalhadores? Fomentam relações democráticas ou autoritárias? Então, primeiramente, o(a) psicólogo(a) deve se apropriar dos efeitos políticos de suas práticas profissionais. Tendo essa clareza, cremos que poderá contribuir de forma mais explícita para a produção de relações mais humanitárias, solidárias e de democratização nos distintos espaços institucionais. Os desafios enfrentados são tamanhos que não devemos nos perder em conflitos personalistas e de manutenção das 
hierarquias e lugares de poder instituídos. A democracia é uma prática coletiva que está em permanente construção. Defendê-la significa colocar a Psicologia ao lado da maior parte da população, ao lado daquelas(es) que estão lutando por uma vida justa e digna. Então, acreditamos que este número temático irá contribuir para consolidar uma reflexão permanente e relevante sobre a função, o papel e as implicações da Psicologia na construção da história de um país, e de outros mundos possíveis, diferentes das opressões e microfascismos que vemos emergir.

Para finalizar, gostaríamos de agradecer os plenários do CFP e do Sistema-Conselhos de Psicologia, que, desde a década de 1980, vêm construindo uma
Psicologia brasileira mais crítica e comprometida com a vida e as minorias sociais (que são as maiorias do ponto de vista numérico). Dentre tantas(os) psicólogas(os), agradecemos o conselheiro Pedro Paulo Bicalho, que, além de ser militante de direitos humanos, construiu conosco a ideia deste número temático e a Editora da Revista Psicologia: Ciência e Profissão, Professora Neuza Guareschi, que acolheu entusiasticamente esta proposta. Também não podemos esquecer o trabalho e empenho dos pareceristas, professores(as) e pesquisadores(as) de importantes Universidades do país, que mesmo estando com a agenda lotada, contribuíram com as avaliações dos artigos em tempo recorde.

\section{Referências}

Ansara, S. (2008). Memória política, repressão e ditadura no Brasil. Curitiba, PR: Juruá.

Arantes, M.A.A.C. (1994). Pacto re-velado: psicanálise e clandestinidade política. São Paulo, SP: Escuta.

Coimbra, C.M.B. (1995). Guardiões da Ordem: uma viagem pelas práticas psi no Brasil do 'milagre'. Rio de Janeiro, RJ: Oficina do Autor.

Conselho Federal de Psicologia - CFP. (2013). A verdade é revolucionária: testemunhos e memórias de psicólogas e psicólogos sobre a ditadura civil-militar brasileira (1964-1985). Brasília, DF: Conselho Federal de Psicologia.

Conselho Federal de Psicologia - CFP. (1999). Resolução CFP No 001/99, de 22 de março de 1999. Estabelece normas de atuação para os psicólogos em relação à questão da Orientação Sexual. Recuperado de http://pol.org.br/ legislacao/pdf/resolucao1999_1.pdf

Correia, A. M. B., \& Dantas, C. N. C. B. (2017). O fazer psicológico no período da Ditadura Civil-Militar. Psicologia: Ciência e Profissão, 37(num esp), 71-81.

Deleuze, G. (1997). Crítica e clínica. São Paulo, SP: Ed. 34.

Dobles, I. (2009). Memorias del dolor: consideraciones de las comisiones de la verdad en America Latina. San Jose: Arlekín.

Foucault, M. (1999). Em defesa da sociedade: curso dado no Collège de France (1975-1976). São Paulo, SP: Martins Fontes.

Furlan, V. (2017). Psicologia e a Política de Direitos: percursos de uma relação. Psicologia: Ciência e Profissão, 37(num esp), 91-102.

Hur, D.U. (2012). Políticas da psicologia: histórias e práticas das associações profissionais (CRP e SPESP) de São Paulo, entre a ditadura e a redemocratização do país. Psicologia USP, 23(1), 69-90. https:// doi.org/10.1590/S0103-65642012000100004

Hur, D.U. (2013). Esquizoanálise e política: proposições para a Psicologia Crítica no Brasil. Teoría y Crítica de la Psicología, (3), 264-280. Recuperado de http://www.teocripsi.com/ojs/index.php/TCP/article/view/111

Hur, D. U., \& Lacerda Jr., F. (2017). Ditadura e insurgência na América Latina: Psicologia da Libertação e resistência armada. Psicologia: Ciência e Profissão, 37(num esp), 28-43.

Huyssen, A. (2002). En busca del futuro perdido: cultura y memoria en tiempos de globalización. México, DF: FCE.

Jardim, L. E. F. (2017). Psicologia social e pesquisa com memória: método e reparação de danos da ditadura civil-militar. Psicologia: Ciência e Profissão, 37(num esp), 103-115.

Lira, E \& Piper, I. (orgs.) (1997). Subjetividad y política: diálogos en América Latina. Santiago, Chile: Instituto Latinoamericano de Salud Mental y Derechos Humanos.

Lira, E., Weinstein, E., \& Kovalskys, J. (1987). Subjetividad y represión política: intervenciones psicoterapéuticas. In M. Montero (ed.), Psicología política latinoamericana (pp. 317-346). Caracas: Panapo, 1987. 
Naffah Neto, A. (1985). Poder, vida e morte na situação de tortura: esboço de uma fenomenologia do terror. São Paulo, SP: Hucitec.

Puget, J. (2000). Traumatismo social: Memoria social y sentimiento de pertenencia: memória social-memoria singular. Psicoanálisis APdeBA, 22(2), 455-482. Recuperado de http://www.apdeba.org/wp-content/uploads/022000puget.pdf

Puget, J., \& Kaës, R. (1991). Violencia de estado y psicoanálisis. Buenos Aires: Centro Editor de América Latina. Asamblea Permanente por los Derecho Humanos.

Páez, D., Espinosa, A., \& Beristain, C. M. (2015). Dossier sobre el impacto psicosocial de las comisiones de la verdad y otros procesos de justicia transicional en países de América Latina. Revista Psicologia Política, 15(32), 97-100. Recuperado de http://pepsic.bvsalud.org/scielo.php?script=sci_issuetoc\&pid=1519-549X20150001\&lng=pt\&nrm=iso

Rodrigues, H. B. C., Fernandes, P. J., \& Duarte, M. G. S. (2001). Breve história da constituição do grupo Plataforma Argentino. In A. M. Jacó-Vilela, A. C. Cerezzo, H. B. C. Rodrigues (orgs.), Clio-Psyché hoje. fazeres e dizeres psi na história do Brasil. Rio de Janeiro, RJ: Relume Dumará.

Silva, F. F. (2017). Psicologia no contexto da ditadura civil militar e ressonâncias na contemporaneidade. Psicologia: Ciência e Profissão, 37(num esp), 82-90.

Vázquez, F. (2001). La memoria como acción social. Relaciones, significados e imaginario. Barcelona: Paidós.

Viñar, M. (1992). Exílio e tortura. São Paulo, SP: Escuta.

Viñar, M.U. (1997). Notas para pensar el terror de Estado y sus efectos en la subjetividad. Revista Uuguaya de Psicoanálisis, (86). Recuperado de http://www.apuruguay.org/apurevista/1990/1688724719978614.pdf

\section{Fernando Lacerda Júnior}

Graduado e doutor em Psicologia pela Pontifícia Universidade Católica de Campinas, Campinas - SP. Brasil. Professor adjunto de graduação e pós-graduação em Psicologia da Universidade Federal de Goiás, Goiânia - GO. Brasil. Ex-presidente da Associação Brasileira de Psicologia Política (2014-2016).

E-mail: fernando_lac@yahoo.com.br

\section{Domenico Uhng Hur}

Graduado, mestre e doutor em Psicologia Social pela Universidade de São Paulo. Professor adjunto de graduação e pós-graduação em Psicologia da Universidade Federal de Goiás, Goiânia - GO. Brasil. Editor da Associação Ibero-latino-americana de Psicologia Política (2016-2018). Atualmente realiza pós-doutorado na Universidade de Santiago de Compostela, Espanha.

E-mail: domenicohur@hotmail.com

Ambos são organizadores e coautores de sete livros e dezenas de artigos científicos nas áreas de Psicologia Social e Psicologia Política.

Como citar: Hur, D.U., \& Lacerda Júnior, F. (2017). Psicologia e democracia: da ditadura civil-militar às lutas pela democratização do presente. Psicologia: Ciência e Profissão, 37(n. spe), 3-10.

https://doi.org/10.1590/1982-3703190002017

How to cite: Hur, D.U., \& Lacerda Júnior, F. (2017). Psychology and Democracy: from the Civil-Military Dictatorship to the Struggles for the Democratization of the Present. Psicologia: Ciência e Profissão, 37(n. spe), 1-8. https://doi.org/10.1590/1982-3703190002017

Cómo citar: Hur, D.U., \& Lacerda Júnior, F. (2017). Psicología y Democracia: de la Dictadura Civil-Militar a las Luchas por la Democratización del Presente. Psicologia: Ciência e Profissão, 37(n. spe), 1-8. https://doi.org/10.1590/1982-3703190002017 